\title{
Evaluation of protein secondary structure from FTIR spectra improved after partial deuteration
}

\author{
Joëlle De Meutter ${ }^{1}$. Erik Goormaghtigh ${ }^{1}[\mathbb{D}$
}

Received: 12 October 2020 / Revised: 8 January 2021 / Accepted: 13 January 2021 / Published online: 3 February 2021

(c) The Author(s) 2021

\begin{abstract}
FTIR spectroscopy has become a major tool to determine protein secondary structure. One of the identified obstacle for reaching better predictions is the strong overlap of bands assigned to different secondary structures. Yet, while for instance disordered structures and $\alpha$-helical structures absorb almost at the same wavenumber, the absorbance bands are differentially shifted upon deuteration, in part because exchange is much faster for disordered structures. We recorded the FTIR spectra of 85 proteins at different stages of hydrogen/deuterium exchange process using protein microarrays and infrared imaging for high throughput measurements. Several methods were used to relate spectral shape to secondary structure content. While in absolute terms, $\beta$-sheet is always better predicted than $\alpha$-helix content, results consistently indicate an improvement of secondary structure predictions essentially for the $\alpha$-helix and the category called "Others" (grouping random, turns, bends, etc.) after $15 \mathrm{~min}$ of exchange. On the contrary, the $\beta$-sheet fraction is better predicted in non-deuterated conditions. Using partial least square regression, the error of prediction for the $\alpha$-helix content is reduced after 15 -min deuteration. Further deuteration degrades the prediction. Error on the prediction for the "Others" structures also decreases after 15-min deuteration. Cross-validation or a single 25-protein test set result in the same overall conclusions.
\end{abstract}

Keywords FTIR spectroscopy $\cdot$ Secondary structure $\cdot$ Protein spectroscopy $\cdot$ Protein microarrays $\cdot$ Hydrogen deuterium exchange

\section{Introduction}

Proteins are widely used as therapeutics in the biopharmaceutical industry and in food industry (Dimitrov 2012). Their characterisation is an essential step in the development and quality control processes (Raynal et al. 2014; Rogstad et al. 2019). Quality is indeed an essential parameter for drug approval by the FDA and other similar agencies. Proteins are prone to structural modification during production, storage and transport (shaking). Protein characterization is made arduous by their complexity, size and unstable 3D structure. This highlights the importance of monitoring and quickly

Special Issue: COST Action CA15126, MOBIEU: Between atom and cell.

Erik Goormaghtigh

egoor@ulb.ac.be

1 Center for Structural Biology and Bioinformatics,

Laboratory for the Structure and Function of Biological

Membranes, Campus Plaine CP206/02, Université Libre de

Bruxelles, B1050 Brussels, Belgium obtaining information on the structure of a protein set. Fourier transform infrared spectroscopy (FTIR) is a powerful tool to assess protein secondary structure (Byler and Susi 1986; Susi and Byler 1986a; Surewicz and Mantsch 1988; Goormaghtigh et al. 1990, 2006, 2009; Lee et al. 1990; Prestrelski et al. 1992; Arrondo et al. 1993; Pribic et al. 1993; Oberg et al. 2003, 2004; Hering et al. 2004; Navea et al. 2005, 2006; Barth 2007; Wang et al. 2008; Wilcox et al. 2016) and simultaneously protein glycan content (Derenne et al. 2020). Recently, we proposed a new approach for evaluating protein secondary structure in a high throughput way, combining infrared imaging and protein microarray printing (De Meutter and Goormaghtigh 2021). We also designed a protein library, made out of 92 soluble proteins (cSP92) carefully selected for spectroscopic calibration and commercially available to everyone (De Meutter and 
Goormaghtigh 2020b). The protein library is well characterized and we have shown how the structures present in the set cover the space of secondary structures and folds described by CATH classification (Orengo et al. 1997). Moreover, we also showed how the relatively small set of proteins present in cSP92 presents similar distribution of structural features as the overall protein set described in the PDB. The FTIR spectra obtained from the 92 calibration set proteins allowed building prediction models of protein secondary structure (De Meutter and Goormaghtigh 2021) based on high performance algorithms used in Chemometrics such as Partial least square (PLS) (Geladi and Kowalski 1986; Wold et al. 2001), Support vector machine (SVM) (Tange et al. 2015; Ghorbani et al. 2016) or Ascending stepwise linear regression (ASLR) (Goormaghtigh et al. 2006, 2009). One of the identified potential obstacles for reaching better predictions is the strong overlap of the bands assigned to different secondary structure types in the amide vibration region of the spectrum. It is well known that amide I (about $80 \% \mathrm{C}=\mathrm{O}$ stretching) and amide II (mainly $\delta(\mathrm{N}-\mathrm{H}$ and $\nu(\mathrm{C}-$ $\mathrm{N})$ ) bands are the most useful for secondary structure determination (Susi 1972). In the amide I band, the disordered structures and $\alpha$-helical structures absorb almost at the same wavenumber (Byler and Susi 1986; Susi and Byler 1986b; Goormaghtigh et al. 1990), reviewed in (Goormaghtigh et al. 1994a). A potential way to improve accuracy of secondary structure evaluation would be to use exchange of hydrogen atoms of the protein by deuterium (HDX) to better separate the absorption bands (Zuber et al. 1992; Iloro et al. 2008). Indeed, in amide I band, HDX induces a slight of $5-10 \mathrm{~cm}^{-1}$ to lower wavenumbers upon N-H deuteration (Susi 1972), reviewed in (Goormaghtigh et al. 1994a), while the amide II disappears and a new band, called amide II', appears about $100 \mathrm{~cm}^{-1}$ below. It must be noted that the smaller shifts reported in the literature $\left(<10 \mathrm{~cm}^{-1}\right)$ are likely to be due to incomplete deuteration as, when proteins are fully deuterated, e.g. obtained from cells growing in ${ }^{2} \mathrm{H}_{2} \mathrm{O}$ (Sivakumar et al. 2005), the shift is around $12 \mathrm{~cm}^{-1}$. A key factor is that exchange is expected to proceed much more rapidly for peptidic elements that are more exposed and/or less stable, as the unordered fraction is expected to be. For structured polypeptide chains, exchange is indeed slow and rates are determined by the small fraction of the time that the protein experiences in a transiently unfolded conformation (Hvidt and Nielsen 1966; Englander and Kallenbach 1983a; Englander et al. 2003; Zhang 2020). The displacement of the Amide I band of the unordered fraction to lower wavenumbers should therefore initially result in a better separation from the band assigned to $\alpha$-helices. Baello et al. already showed improved prediction of protein secondary structure on a set of 19 proteins in solution after partial HD exchange (Baello et al. 2000).

While measuring spectra of proteins at different stage of HD exchange is tedious, it becomes particularly convenient upon combining microarray printing and infrared imaging (De Meutter et al. 2016, 2017). Indeed, a cell formed by the microarray-bearing $\mathrm{BaF}_{2}$ slide and a clean $\mathrm{BaF}_{2}$ slide separate from the first one by a spacer can be flushed by ${ }^{2} \mathrm{H}_{2} \mathrm{O}$-saturated $\mathrm{N}_{2}$ flow. Exchange occurs, then simultaneously for all proteins and single images covering ca 96 spots of proteins can be recorded on-line at selected time points. The advantage of this method is that it allows the simultaneous recording of all the spectra of the proteins printed on a microarray, at any HD exchange time.

This work highlights an improvement of secondary structure predictions essentially for the $\alpha$-helix and the category called "Others" (grouping random, turns, bends, etc.) in partial HDX conditions. On the contrary, $\beta$-sheet fraction is better predicted in non-deuterated conditions.

\section{Materials and methods}

\section{Proteins}

The proteins used in this work are a subset of the cSP92 protein library. The list of the proteins has been published with their commercial source and their characterization (sequence, purity,...) (De Meutter and Goormaghtigh 2020b). Seven proteins of cSP92 were discarded due to the poor quality of the spectra. This low quality was the result of low-protein concentration related to the small quantities available, of the passage of the IR beam through $2 \mathrm{BaF}_{2}$ windows and of the use of the $4 \times$ objective required to observe simultaneously 96 protein spots (see below). Table S1 reports the subset of 85 proteins selected. Protein samples were solubilized at a final concentration of $10-20 \mathrm{mg} / \mathrm{ml}$ in $4 \mathrm{mM}$ Hepes, $85 \mathrm{mM} \mathrm{NaCl}$. Buffer solutions were filtered on $0.2 \mu \mathrm{m}$ filters before use. To avoid contributions of the original buffer, salts and/or additives of preparation or purification, samples were de-salted and buffers exchanged against $4 \mathrm{mM}$ Hepes, $85 \mathrm{mM} \mathrm{NaCl}$ (5\%), pH between 7.4 and 7.6 except for a few proteins as described in (De Meutter and Goormaghtigh 2020b). Buffer exchange of ca $100 \mu$ sample was achieved through filtration by 5 repetitive cycles (Amicon Ultra- $0.5 \mathrm{ml}$ Centrifugal Filters $3 \mathrm{~K}$ ). Around $75 \mu \mathrm{l}$ were collected. Alternatively, they were passed twice through size exclusion centrifuge mini column (Bio-Rad Micro Bio-Spin $3 \mathrm{kD})$ equilibrated with buffer. Purity and integrity of the acquired proteins were then controlled by SDS Page (4-20\% 
Mini-PROTEAN Precast Protein Gels, Bio-Rad), all protein used were found to have a purity larger than $85 \%$.

\section{Protein microarrays printing}

The experimental procedure is described in detail elsewhere (De Meutter et al. 2016, 2017); $100 \mathrm{pl}$ protein drops (proteins dissolved at $5-10 \mathrm{mg} \mathrm{ml}^{-1}$ in $2 \mathrm{mM}$ Hepes buffer $\mathrm{pH} 7.0 /$ ethylene glycol 1/1 v/v) have been printed with an Arrayjet Marathon noncontact inkjet Microarrayer (ArrayJet, Roslin, $\mathrm{UK}$ ) forming microarrays on $\mathrm{BaF}_{2}$ surfaces. Spot diameter was about $80 \mu \mathrm{m}$. Spot-to-spot distances in the $\mathrm{X}$ and $\mathrm{Y}$ directions were $200 \mu \mathrm{m}$, resulting in ca 2,000 protein samples per $\mathrm{cm}^{2}$. Before use, the protein microarrays were dried in a dessicator under vacuum. All proteins were recorded in quadruplicates obtained from the same batch of protein.

\section{FTIR imaging of protein microarrays}

FTIR imaging of protein microarrays has been described earlier (De Meutter et al. 2016, 2017). Spectra were recorded as the average of 64 scans per pixel, between 3650 and $900 \mathrm{~cm}^{-1}$ at a nominal resolution of $8 \mathrm{~cm}^{-1}$. FTIR data were collected in transmission mode using an Agilent midIR imager equipped with a liquid nitrogen cooled $128 \times 128$ Mercury Cadmium Telluride (MCT) Focal Plane Array (FPA) detector and a $4 \times$ objective.

Automated spectrum extraction has already been described (De Meutter et al. 2017), including the procedure followed to subtract the background. With the $4 \times$ objective, a single protein spot usually contained ca 20 pixels, i.e. 20 spectra. After correction for background, spectra filtered for signal-to-noise ratio and maximum absorbance were averaged. Finally, the average spectra of quadruplicates obtained for a same protein were averaged, yielding one spectrum per protein. Spectra were then baseline-corrected by subtraction of a straight line interpolated between the spectral points at 1720 and $1480 \mathrm{~cm}^{-1}$. Scaling was obtained by vector normalization between 1720 and $1590 \mathrm{~cm}^{-1}$. Precise peak position (Figure S2) was obtained by fitting 11 data points before and after the approximate maximum by a third-order polynomial and finding the roots of its derivative as described (Derenne et al. 2013).

\section{Hydrogen deuterium exchange}

A homemade sealed cup was designed specifically for this experimentation. The assembly consisted of two $\mathrm{BaF}_{2}$ slides used in turn to form a vessel, the bottom one supported the printed microarray and the top one closed the cell. In between, along the edges of the slides, $\mathrm{UHU}^{\circledR}$ Patafix adhesive paste (Bolton Adhesives) was used to hermetically seal the two surfaces and two pieces of catheter ensured the entry and exit of ${ }^{2} \mathrm{H}_{2} \mathrm{O}$-saturated nitrogen flow. A $\mathrm{N}_{2}$ flow bubbled in 3 vials containing ${ }^{2} \mathrm{H}_{2} \mathrm{O}$ placed in series before being sent to the sample at a flow rate of $100 \mathrm{ml} / \mathrm{min}$. Once vessel and catheters were set up and positioned under the microscope, the focus was adjusted and the device remained in place for the whole duration of the exchange experiment (about $24 \mathrm{~h}$ ). The use of a $4 \times$ objective allowed recording an entire microarray in one single image. A microarray with 96 spots covered an area of about $3.75 \mathrm{~mm}^{2}$. The area of a $4 \times$ magnification infrared image covers $6.9 \mathrm{~mm}^{2}$. IR images of the microarrays were recorded at 4 deuteration times: $t_{0}$, no deuteration; $\mathrm{t}_{15}: 15^{\prime} 25^{\prime \prime} \pm 1^{\prime} ; \mathrm{t}_{105}: 1 \mathrm{~h} 45^{\prime} \pm 12^{\prime}$ and $\mathrm{t}_{24 \mathrm{~h}} 24 \mathrm{~h} \pm 1 \mathrm{~h}$ the day after.

\section{Secondary structures}

In this work, secondary structure content are reported in $\%$ of the total amino acid content. The identities of the highresolution PDB files obtained from the PDB repository was previously reported along with the secondary structure content obtained by applying the DSSP algorithm (De Meutter and Goormaghtigh 2020b). According to DSSP nomenclature, $\alpha$-helix is symbolized by the letter $\mathrm{H}$ and $\beta$-sheet by $\mathrm{E}$ (Kabsch and Sander 1983). The "minor" structures such as $3_{10}$-helix (G), $\pi$-helix (I), helix-turn (T), beta bridge (B) and bend (S) defined by DSSP could not be predicted with sufficient accuracy (De Meutter and Goormaghtigh 2021) and will not be investigated independently here. We therefore define a category called "Others" computed as 100-H-E. As previously proposed by (Kalnin et al. 1990), the $\alpha$-helix structure was split into "ordered" and "disordered" helix. The "ordered" helix content was obtained after amputation of two amino acids residues at both ends of the $\alpha$-helices. The tips of the $\alpha$-helices not included in the previous group are assigned to "disordered" helix fraction. It was originally reported that parallel and antiparallel $\beta$-sheet cannot be differentiated (Susi and Byler 1987) but it has also been shown in a number of cases that parallel and antiparallel $\beta$-sheets have distinct FTIR spectra (Cerf et al. 2009; Celej et al. 2012). The $\beta$-sheet structure was therefore split into parallel and antiparallel $\beta$-sheet, respectively. It was found (data not shown) that the parallel $\beta$-sheet and ordered $\alpha$-helix contents could not be predicted satisfactorily because of too low variance in the protein set. Results will not be further discussed here. On the contrary, the $\alpha$-helix, ordered $\alpha$-helix, $\beta$-sheet, antiparallel $\beta$-sheet, and "Others" structure contents present enough variance in the protein set to generate good prediction models. Content in ordered/disordered helix and parallel/antiparallel $\beta$-sheet were compiled from DSSP files. All structural features have been extracted and tabulated from the DSSP files by a module of the home-made Kinetics software running under Matlab, as described in (De Meutter and Goormaghtigh 2020b). 


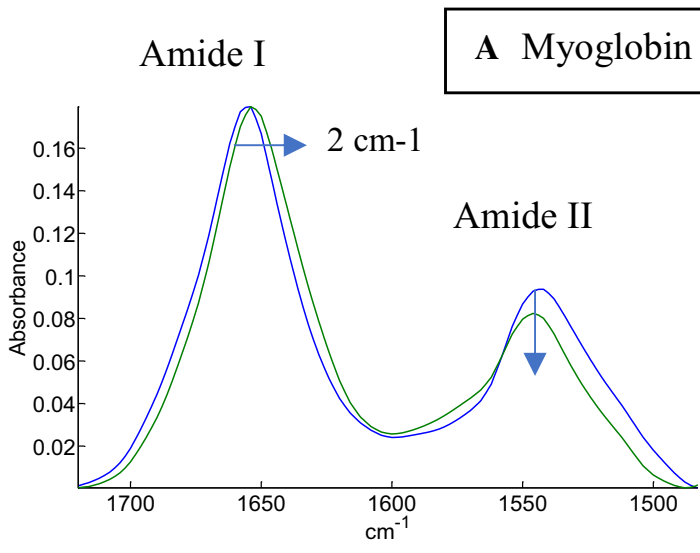

Fig. 1 Effect of 15 min deuteration on myoglobin and metallothionein infrared spectra in the amide I-amide II spectral range. Spectra shown at $\mathrm{t}_{0}$ (blue lines) and $\mathrm{t}_{15}$ (green lines) for myoglobin (a) and

\section{Chemometrics}

Partial least square regression (PLS) adequately addresses the problem of co-linearity in multivariate linear regressions (Geladi and Kowalski 1986; Wold et al. 2001). PLS regression was obtained by the software running under Matlab developed by (Nørgaard et al. 2000; Leardi and Nørgaard 2005). Support vector machine (SVM) regression was developed by (Suykens and Vandewalle 1999; Suykens et al. 2002) to deal with non-linear regressions. Computations were obtained with the Matlab toolbox created by the authors (Tange et al. 2015; Ghorbani et al. 2016). Ascending stepwise linear regression (ASLR) was described earlier (Goormaghtigh et al. 2006, 2009). The ascending stepwise linear regression introduces in the model one absorbance value at a time, in an ascending stepwise manner. The result is a linear equation requiring usually only $2-4$ absorbance values to obtain a given secondary structure content.

A first validation was obtained by a leave-one-out (LOO) cross-validation. In LOO cross-validation, the evaluation of the error is not based on repeated measurements of the same sample but it uses the full set information to validate the model. One protein at a time was removed from the training set and tested by the model built using the 84 remaining proteins. This was repeated 85 times. The quality of the prediction was evaluated as the root mean square standard error in cross-validation (RMSECV). This error was compared with the standard deviation of the reference (i.e. DSSP values) secondary structure content (STDDEV ${ }^{\text {REFCV }}$ ) by computing $\zeta^{\mathrm{CV}}=\mathrm{STDDEV}^{\mathrm{REFCV}} / \mathrm{RMSECV}$. While STDDEV ${ }^{\mathrm{REFCV}}$ is the error of prediction that would be obtained if guessing that the secondary structure content for each protein is the mean secondary structure in the protein set, $\zeta^{\mathrm{CV}}$ value reports how much better the model based on spectroscopic data does. It is interesting to note that $\zeta$ is inversely related

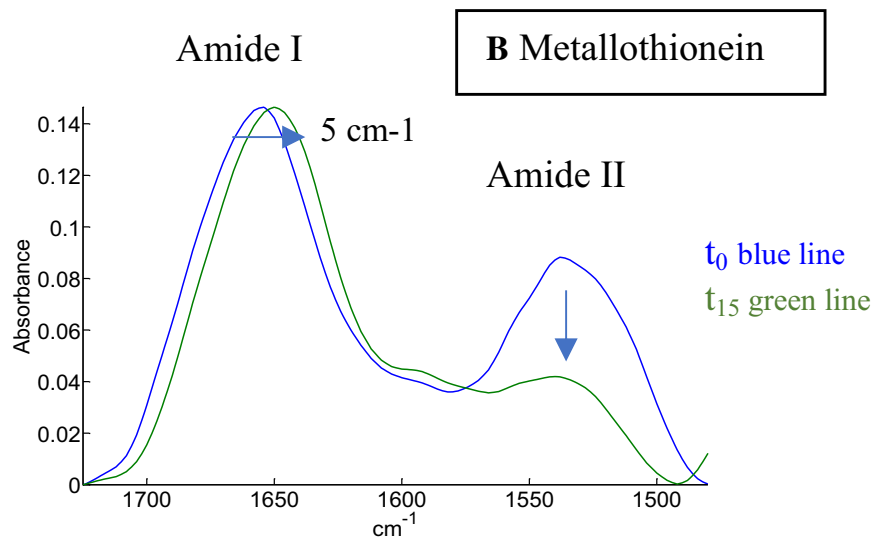

metallothionein (b). An arrow indicates the direction of the changes induced by 15 -min deuteration

to the square of the correlation coefficient (Fearn 2002). To obtain an independent test set for validation, a single subset of the cSP92 protein spectra was identified using the Kennard-Stone algorithms (Kennard and Stone 1969) that is designed to select a uniform distribution of the secondary structure content. In the present work, 25 proteins were used as test set and 60 for the training set. The error of prediction RMSEKS and $\zeta^{\mathrm{KS}}=$ STDDEV ${ }^{\mathrm{REFKS}} / \mathrm{RMSEKS}$ were computed as described above.

\section{Software}

Image analysis, spectrum processing and multivariate analyses were all performed with Kinetics, a home-made software running under MatLab (The MathWorks Inc.). The software is freely available for academics upon request.

\section{Results}

Infrared images of the microarrays were recorded at 4 time points of the H/D exchange process as described in Material and Methods. A subset of 85 proteins was selected from the cSP92 proteins, after elimination of 7 proteins with poor quality spectra (Table S1). Figure S1 reports the spectra of a highly helical protein spectrum, myoglobin, and a highly disordered protein, metallothionein at $\mathrm{t}_{0}, \mathrm{t}_{15}$, $t_{105}, t_{24 h}$ between 3600 and $1050 \mathrm{~cm}^{-1}$. The main contributions of ${ }^{1} \mathrm{H}_{2} \mathrm{O},{ }^{1} \mathrm{HO}^{2} \mathrm{H},{ }^{2} \mathrm{H}_{2} \mathrm{O}$ along with the main protein amide contributions are identified on Figure S1. Figure 1 illustrates the effect of 15-min HDX in the amide I-amide II spectral range for myoglobin and metallothionein. Before exchange $\left(\mathrm{t}_{0}\right)$, the amide I maximum is located at $1655 \mathrm{~cm}^{-1}$ for myoglobin as well as for metallothionein, i.e. the contribution of $\alpha$-helix and disordered structure overlaps to a large 


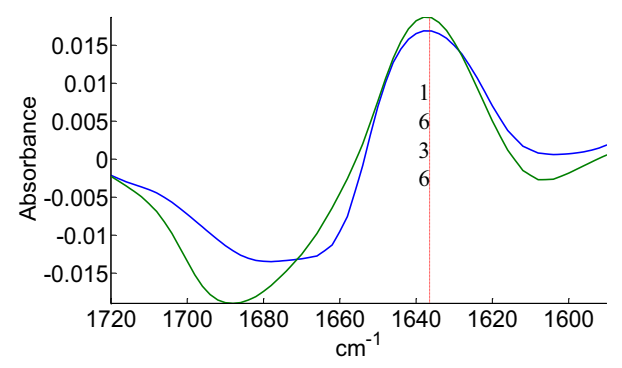

Fig. 2 Difference between spectra at $\mathrm{t}_{15}$ and $\mathrm{t}_{0}$ HDX time for myoglobin (blue) and metallothionein (green). Absorbance at the maximum at $1636 \mathrm{~cm}^{-1}$ is indicated

extend though the metallothionein band is broader than the myoglobin one (Fig. 1, blue curves). After 15 min deuteration $\left(\mathrm{t}_{15}\right)$, Amide I shifts to $1653 \mathrm{~cm}^{-1}$ for myoglobin and $1650 \mathrm{~cm}^{-1}$ for metallothionein. Reproducibility is evaluated for the quadruplicates in Figure S2. It must also be stressed that hydration of the film resulting from the addition of ${ }^{2} \mathrm{H}_{2} \mathrm{O}$ in the $\mathrm{N}_{2}$ flow flushing the cell could explain a $1-2 \mathrm{~cm}^{-1}$ downshift of the amide I (see the discussion section). Concomitantly, a large difference is observed between the $\mathrm{t}_{15}$-deuterated protein spectra in the amide II band, indicating a much larger extent of the exchange for metallothionein. HDX causes indeed a reduction of amide II and the simultaneous appearance of amide II' around $1450 \mathrm{~cm}^{-1}$ (amide II' not shown, see Figure S1). It must be mentioned here that the mixed ${ }^{2} \mathrm{H}-\mathrm{O}-{ }^{1} \mathrm{H}$ molecule also absorbs at $1450 \mathrm{~cm}^{-1}$ (Zuber et al. 1992; Goormaghtigh et al. 1994b). Yet, this contribution is expected to be very small as the sample compartment is flushed with a continuous flow of ${ }^{2} \mathrm{H}_{2} \mathrm{O}$-saturated $\mathrm{N}_{2}$. Any ${ }^{1} \mathrm{H}_{2} \mathrm{O}$ present at the beginning of the experiment would therefore be very rapidly replaced and removed from the cell. The larger extent of exchange in the disordered structure promotes a larger difference in the amide I band position, suggesting that $\alpha$-helices of myoglobin may be easier to distinguish from disordered structures after a $t_{15}$ HDX period. Such a difference in exchange rates can be assigned to the difference in secondary structure. Intrinsically disordered proteins such as metallothionein $(0 \% \mathrm{H}, 0 \%$, E, $100 \%$ "Others") have amide protons more accessible than in well-structured helical protein such as myoglobin $(73 \% \mathrm{H}$, $0 \% \mathrm{E}, 27 \%$ "Others") where the amide protons are involved in strong $\mathrm{H}$ bonds within the helical structures.

The effect of deuteration at $t_{15}$ is better appreciated after subtracting the $t_{15}$ spectrum from the $t_{0}$ one. The difference spectrum is shown in Fig. 2 for myoglobin (blue) and metallothionein (green). A positive deviation around $1636 \mathrm{~cm}^{-1}$ is observed in both cases. This means that the rapidly exchanged amide fraction now overlaps the $\beta$-sheet absorption band. This observation suggests it may be more challenging to quantify $\beta$-sheet content after 15 min HDX.

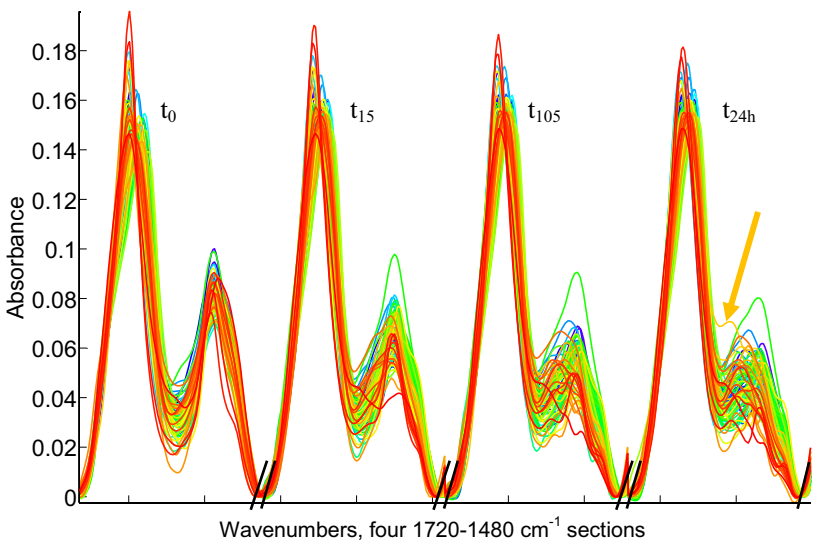

Fig. 385 concatenate spectra of 4 deuteration exchange period of time, $t_{0}, t_{15}, t_{105}$ and $t_{24 h}$ as indicated on the figure. Spectra were sorted in ascending order of disordered structure content from low (blue) to high (red). Each interval begins at 1720 and ends at $1480 \mathrm{~cm}^{-1}$. Limits between intervals are indicated on the abscissa by $/ /$. The spectrum of glucagon indicated by the arrow at $t_{24 h}$ is discussed in the Discussion section of the paper

As many previous works, mentioned in the introduction, already demonstrated that amide I-amide II region of the protein spectrum (located between 1700 and $1500 \mathrm{~cm}^{-1}$ ) is the most informative regarding protein secondary structure assessment, we restricted the analysis to this spectral range. For the sake of the simplicity of the analysis, as well as for considering potential synergies between different deuteration periods of time, the $1720-1480 \mathrm{~cm}^{-1}$ spectral region corresponding to the $4 \mathrm{HDX}$ periods were placed side by side to form a single spectrum for each protein. Concatenate spectra are shown in Fig. 3 for the 85 proteins.

Each combined spectrum now counts 4 regions corresponding to the 4 deuteration periods: $\mathrm{t}_{0}, \mathrm{t}_{15}, \mathrm{t}_{105}$ and $\mathrm{t}_{24 \mathrm{~h}}$ recorded between 1720 and $1480 \mathrm{~cm}^{-1}$ (amide I and II bands). An overall decrease in amide II is already visible at the first exchange time $t_{15}$.

As spectra are sorted in Fig. 3 according to their content in disordered structure, it can be observed that the highly disordered proteins (red spectra) display in general a faster drop in amide II intensity at $t_{15}$ than the blue ones. This becomes less clear after $24 \mathrm{~h}$ deuteration at $\mathrm{t}_{24 \mathrm{~h}}$ as amide II of blue and red spectra tend to overlap. While after $24 \mathrm{~h}$ exchange can be far from complete for highly structured proteins (Downer et al. 1986; Vigano et al. 2004), it must be stressed that a very significant part of the absorbance left in the amide II spectral range is due to contributions of amino acid side chains as reviewed in (Goormaghtigh et al. 1994c; Barth 2000, 2007; Wolpert and Hellwig 2006). Depending on side chain composition, this contribution varies but is expected to be around $20 \%$ of the amide intensity (Chirgadze et al. 1975; Rahmelow et al. 1998). Deuteration of side chain brings further contributions to the dip located 
between amide I and amide II bands, for instance, from arginine (Chirgadze et al. 1975), which explains in part the remaining or even increasing intensity observed between amide I and amide II bands.

\section{Partial least squares PLS}

In a first approach, we applied the PLS linear regression method where the predictor variables are the infrared spectra and the dependent variables are the related fractions of secondary structure elements provided by DSSP. The PLS linear regression method was applied on the 85 combined spectra. We first determined the optimal number of latent variables (LVs) specific to each interval corresponding to each deuteration time period and for each structure ( $\alpha$-helices, ordered $\alpha$-helices, $\beta$-sheet, antiparallel $\beta$-sheet and "Others") as in PLS, the calculation is made independently for each structure. The interval PLS method (iPLS) developed by (Nørgaard et al. 2000) was convenient to analyse portions of the spectral range and was aplied here.

Figure 4 reports the root mean square error in cross validation (RMSECV) of models obtained for each interval, in the case of $\alpha$-helix (A), ordered helix (B), $\beta$-sheet (C), antiparallel $\beta$-sheet (D) and "Others" structures (E). Optimal number of latent variables (LVs) is indicated at the bottom of each interval.

At first glance, major differences immediately appear between $\alpha$-helix, $\beta$-sheet and "Others". For $\alpha$-helix and ordered $\alpha$-helix structures, results are quite similar (Fig. 4a and b), best models (giving the minimal error) are obtained at $\mathrm{t}_{15}$. with 6 LVs. Best models are also obtained at $\mathrm{t}_{15}$ for "Others" with 5 LVs (Fig. 4e). On the contrary, the minimal RMSECV is obtained at $t_{0}$, in the case of $\beta$-sheet with $4 \mathrm{LVs}$ (Fig. 4c) and antiparallel $\beta$-sheet with 7 LVs (Fig. 4d).

In conclusion, the most efficient models, i.e. models resulting in the smallest RMSECV, are obtained after partial deuteration at $t_{15}$ for $\alpha$-helix and "Others" structures. For $\beta$-sheets, $t_{0}$ gives better prediction. Further analyses (not shown) indicate that neither smaller subintervals nor the global model that considers the entire spectral range of the concatenate spectra outperform those found at $t_{0}$ or $t_{15}$ (Table 1). Once subintervals giving the minimum error were identified, models for predicting secondary structure content were built using the best deuteration time. Figure 5 reports for the $\alpha$-helix structure the predicted versus actual content using models built with the $1720-1480 \mathrm{~cm}^{-1}$ spectral range recorded at $\mathrm{t}_{0}$ and $\mathrm{t}_{15}$. Figure 5 indicates a global improvement of the prediction at $t_{15}$ but does not indicate that a specific protein category such as $\alpha$-helix rich proteins is responsible for the improvement. Similar conclusions were reached for $\beta$-sheet and "Others" structures (Figure S3).
The error of prediction in cross validation, RMSECV, is shown in the inset and is reported for all structures in Table 1. The smaller RMSECV was obtained at $t_{15}$ for $\alpha$-helix, RMSECV $=5.68 \%$, compared to $6.24 \%$ at $\mathrm{t}_{0}$. Similarly, the best prediction was obtained at $\mathrm{t}_{15}$ in the case of "Others", RMSECV $=7.13 \%$ instead of $8.13 \%$ at $t_{0}$. On the contrary, lower RMSECV, $6.01 \%$, was obtained for $\beta$-sheet at $\mathrm{t}_{0}$ instead of $6.47 \%$ at $\mathrm{t}_{15}$. When the models were built using a single 25 -protein test set selected by the KennardStone algorithm, the finding is essentially the same, confirming with an independent validation test set the conclusions obtained by LOO cross-validation. It must be noted here that for each structure, the 25 proteins of the validation set were selected independently and a calibration model was constructed with the remaining 60 protein spectra. The spectra selected for the validation test are reported in Table S1 for each structure type and results of the validation test are presented in Table 2.

\section{SVM}

While PLS modelling is based on multiple linear regressions, on the contrary, support vector machine (SVM) algorithm is designed for non-linear regressions. Results obtained by SVM modelling for all fractions considered are summarized in Table 1 (Figure S4 reports the relation between predicted and actual structure content for $\alpha$-helix, $\beta$-sheet and "Others"). Performances are quite similar at $\mathrm{t}_{15}$ and $\mathrm{t}_{0}$ for $\alpha$-helix (RMSECV $=6.14 \%$ and 6.17 , respectively). "Others" structure is better predicted at $\mathrm{t}_{15}$ than at $\mathrm{t}_{0}$ (RMSECV $=7.05 \%$ and $7.75 \%$, respectively) and $\beta$-sheet at $\mathrm{t}_{0}$ than at $\mathrm{t}_{15}$ (RMSECV $=5.80 \%$ and $6.43 \%$, respectively). As for PLS, when the models are built using a single 25-protein test set selected by the Kennard-Stone algorithm, the finding is essentially the same (Table 2), confirming the conclusions obtained by LOO cross-validation on an external validation test set.

\section{ASLR}

Ascending stepwise linear regression is a rather simple approach, which introduces step by step wavenumbers in the model to obtain the best multiple regression. The advantage is that the weight of each wavenumber is immediately apparent. Figure 6 (left column) reports the RMSECV profiles along the entire spectral range of the concatenate spectra when a first wavenumber is chosen, then a second is added and so on. The wavenumber providing the smallest root mean square error in cross validation (RMSECV) is retained at each iteration in the algorithmic process, as shown in Fig. 6 (middle column) for $\alpha$-helix, $\beta$-sheet and "Others" (results obtained for ordered $\alpha$-helix and antiparallel $\beta$-sheet are shown in Fig S5). At each wavenumber added, 

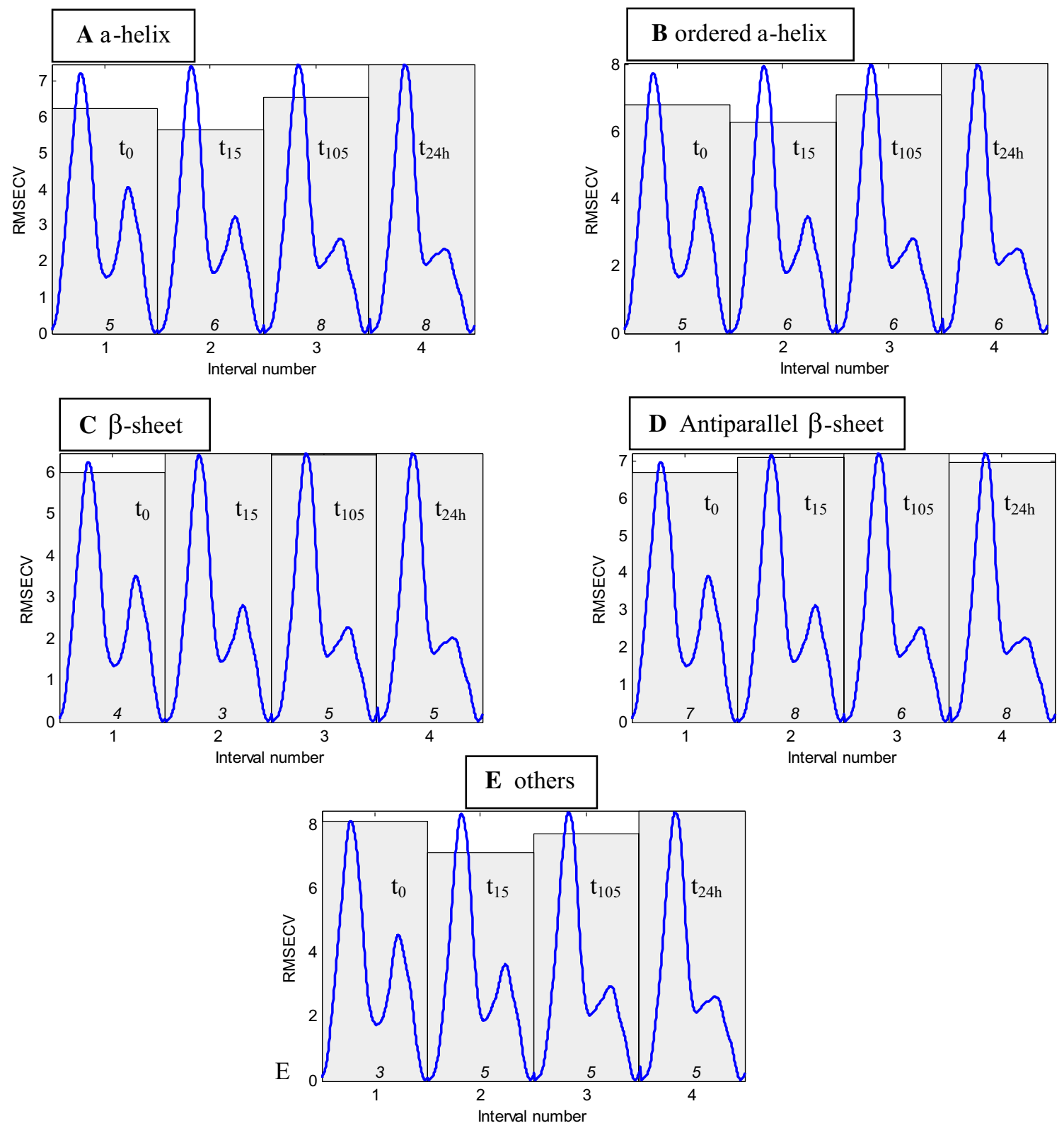

Fig. 4 RMSECV profile obtained by iPLS regression on 4 intervals encompassing the $1720-1480 \mathrm{~cm}^{-1}$ spectral ranges for 85 protein spectra. Each of the 4 intervals, labelled 1, 2, 3 and 4, includes protein spectra obtained, respectively, at $\mathrm{t}_{0}, \mathrm{t}_{15}, \mathrm{t}_{105}$ and $\mathrm{t}_{24 \mathrm{~h}}$ as indicated on the figure. The RMCECV, calculated in leave-one-out cross validation, are indicated by the shaded area for each of the 4 time inter-

the RMSECV value drops, reflecting the improvement of the model. The RMSECV spectral profile (left column,) allows visualizing the information content provided by each wavenumber. For all structures except "Others", it reveals that 4 wavenumbers are enough to extract all relevant information necessary to predict the secondary structure. Addition of the fifth one does not bring more information. On the contrary, for "Others", it appears that 5 wavenumbers are required as there is clearly a level of useful information in vals. The optimal number of LVs to be used for an optimal prediction is indicated at the bottom of each bin. For the sake of the clarity, the mean spectrum at each time point is plotted between 1720 and $1480 \mathrm{~cm}^{-1}$ (units not shown) in blue in the corresponding interval. Data are presented for $\alpha$-helix (a), ordered $\alpha$-helix (b), $\beta$-sheet (c), antiparallel $\beta$-sheet (d) and "Others" (e) content

the fifth RMSECV profile. This is not surprising in view of the wide variety and complexity of the structures present in this group. Best ASLR prediction models obtained with 5 wavenumbers are shown in Fig. 6 right column.

Table 3 reports the wavenumbers selected in order of relevance for each secondary structure and their assignment to one of the 4 deuteration times. A colour code is applied to each deuteration time (green, $\mathrm{t}_{0}$; yellow, $\mathrm{t}_{15} ;$ red, $\mathrm{t}_{105}$ ). It must be noted that $t_{24 h}$ is never selected and is therefore not 


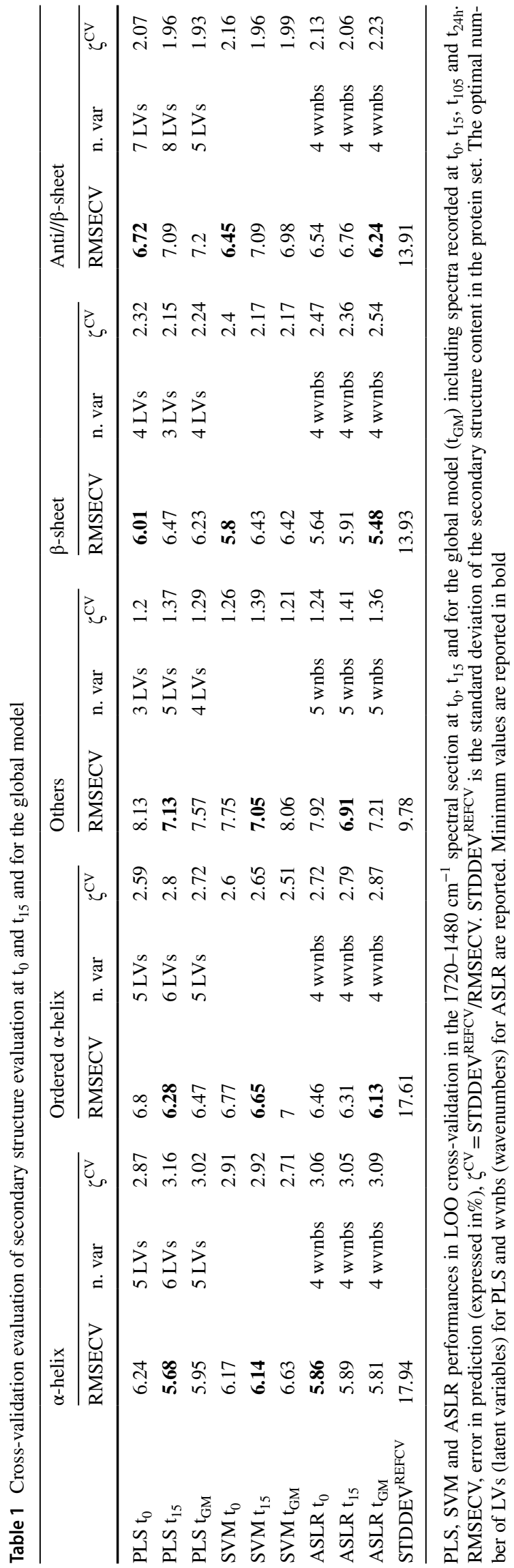

discussed here. Examination of Table 3 reveals that, in the case of $\alpha$-helix, most information is extracted at $t_{15}\left(\mathrm{t}_{15}\right.$ in yellow), around 1655,1627 and $1647 \mathrm{~cm}^{-1}$. For $\beta$-sheet, ordered $\alpha$-helix, anti// $\beta$-sheet and "Others", the first wavenumbers in order of relevance are located at $\mathrm{t}_{0}$. However, some information is drawn from the partially deuterated spectra $\left(\mathrm{t}_{15}\right.$ or $\left.\mathrm{t}_{105}\right)$ for wavenumbers used in third and fourth position.

Unlike the results obtained by PLS and SVM, the best ASLR predictions are obtained when working on concatenate spectra (RMSECV $=5.81 \%$ for $\alpha$-helix, $6.13 \%$ ordered $\alpha$-helix, $5.48 \% \beta$-sheet, $6.24 \%$ antiparallel $\beta$-sheet), except for "Others" structure for which RMSECV is better at $\mathrm{t}_{15}$ (RMSECV $=6.91 \%$, Table 1 ).

Once again, when the models are built using a single 25-protein test set selected by the Kennard-Stone algorithm, the finding is essentially the same (Table 2), confirming the conclusions obtained by LOO cross-validation on an external validation test set.

\section{Discussion}

Table 1 provides an overview of the results obtained by PLS, SVM and ASLR. RMSECV values are reported for all structures. When comparing the different deuteration times, best estimation by PLS and SVM are obtained at $\mathrm{t}_{15}$ for $\alpha$-helix (RMSECV $=5.68-6.14 \%$, respectively) and for "Others" (RMSECV $=7.13$ and $7.05 \%) . \%$ ). In no case was the full model using the entire concatenated spectra better than $t_{15}$ taken alone. As far as the $\beta$-sheet fraction is concerned, it is on the contrary at time $\mathrm{t}_{0}$ that the modelling is more performant by both PLS and SVM (RMSECV $=6.47 \%$ and 5.8). Tables 1 and 2 indicate a relative improvement of $\alpha$-helix and "Others" prediction and a relative degradation of the $\beta$-sheet structure content prediction after a short (15 min) deuteration period. The rationale is that the "Others" structure exchange must faster than the $\alpha$-helix. The "Others" IR contribution in the amide I shifts therefore more rapidly towards lower wavenumbers. As already illustrated in Fig. 1, after 15 min, disordered structures, dominant in the "Others" class, have been mostly exchanged while the $\alpha$-helix structure is not. The consequence is that the overlap of the two contributions is transiently decreased, resulting in an improvement of the predictions for these two structures. As the $\beta$-sheet structure exchange slowly, after $15 \mathrm{~min}$ deuteration, the deuterated contribution of the random structure overlaps the high wavenumber contribution of the $\beta$-sheet, de facto decreasing the quality of the $\beta$-sheet content prediction. Another aspect can explain the relative degradation of $\beta$-sheet content prediction after deuteration. Side chain absorptions present in the amide I amide II range of the spectrum also shift and overlap the $\beta$-sheet spectral region. 
Fig. 5 Relation between predicted and actual $\alpha$-helix content when evaluated at $\mathrm{t}_{0}$ (left panel) and $\mathrm{t}_{15}$ (right panel). Each circle represents a protein. RMSECV, correlation coefficient $r$ and $\xi^{\mathrm{CV}}$ are reported in the inset

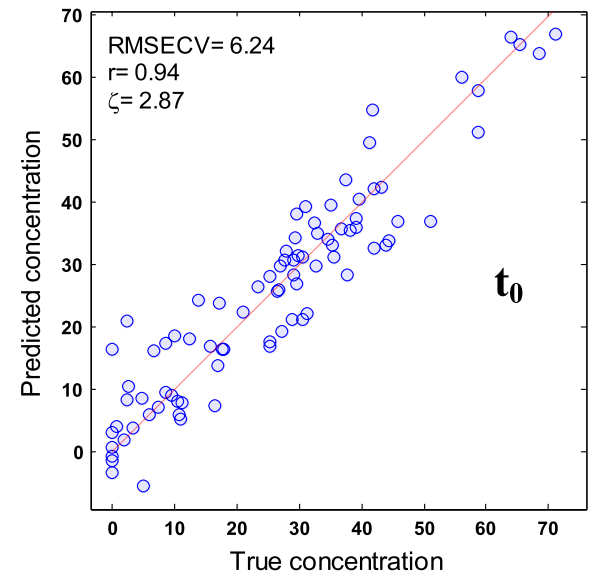

This is particularly significant when the protein is rich in arginine, glutamine, asparagine and lysine. Careful examination of Fig. 3 reveals an orange spectrum, which is obviously more intense near $1600 \mathrm{~cm}^{-1}$ at $\mathrm{t}_{24 \mathrm{~h}}$ than at $\mathrm{t}_{0}$. It is the spectrum of glucagon (indicated by an arrow in Fig. 3) which has an arginine content of $6.9 \%$ and a glutamine content of $10.34 \%$ instead of a mean value of $4.3 \%$ and $3.7 \%$, respectively, in cSP92 protein set. In fact, no other protein has as much glutamine as glucagon in cSP92, the second richest one is ubiquitin with $7.89 \%$. The main absorption band of glutamine is found at $1672 \mathrm{~cm}^{-1}$ in the protonated form (Venyaminov and Kalnin 1991; Wolpert and Hellwig 2006) and $1635 \mathrm{~cm}^{-1}$ in the deuterated form (Chirgadze et al. $1975)$, i.e. exactly where the $\beta$-sheet structure absorbs. The effect of amino acid side chain deuteration is illustrated in Fig. 7. In Fig. 7, glucagon spectrum is represented by the red plain line in the protonated (panel B) and deuterated (panel A) states along with the contribution of the different side chains and their sum (blue line). It is clear that deuteration results in an enhanced absorbance in the $1620-1580 \mathrm{~cm}^{-1}$ spectral range that can interfere with the evaluation of the $\beta$-sheet structure content. After subtraction of the sum of the amino acid side chain contributions, glucagon corrected spectra are presented as dashed lines. The effect is striking. Yet, even though correction for side chain contributions has been attempted (Goormaghtigh et al. 1996; Raussens et al. 2004; Goormaghtigh 2009) and parameters describing side chain band shapes have been reviewed elsewhere (Goormaghtigh et al. 1994c; Barth 2000, 2007), the success of the process is limited by the current impossibility to describe correctly the wealth of variations that exist in these contributions. Yet, Fig. 7 indicates that for glucagon, an improvement is obtained as after correction, the corrected spectrum resembles the usual spectrum of a partially deuterated protein.

The best ASLR models were obtained when considering the entire concatenate spectra instead of $t_{0}$ or $t_{15}$ period alone. This can be understood as ASLR picks up the best wavenumbers one by one and is not disturbed by the rest of the spectrum. Intriguingly, limiting ASLR to one deuteration time $\left(\mathrm{t}_{15}\right)$ improves the prediction for the "Others" structure with respect to the full length concatenated spectra. It must be stressed here that ASLR selects the first best wavenumber, which remains unquestioned when searching for the second one. This one-way path may select a path that is not optimal for the prediction, as exemplified by the observation that restricting the data to $t_{15}$ finally ends up with a better model.

As a preliminary to further discussion, a comment is needed about the measure of the quality of secondary structure evaluations. Two informative quantities regarding the quality of the prediction have been used, the error of prediction (RMSECV) on the one hand and $\zeta^{\mathrm{CV}}$ defined as the ratio of standard deviation of reference values (STDDEV ${ }^{\mathrm{REFCV}}$ ) over RMSECV on the other hand. While the former inform on the absolute error, the latter is a measure of prediction efficiency. Importantly, as the latter refers to STDDEV ${ }^{\mathrm{REFCV}}$, the $\zeta^{\mathrm{CV}}$ figures depend on STDDEV ${ }^{\mathrm{REFCV}}$. Since the standard deviation of the reference data depends on the dataset and is therefore different for each structure and each test set, the $\zeta$ value should therefore be used with caution when comparing $\zeta$ for different structures or different protein test sets. It can be understood that for similar RMSEs (RMSECV and RMSEKS), the $\zeta$ values are generally higher for the 25 -protein test set which has in general higher STDDEV REFKS because spectra are selected, by design, to span homogenously the concentration range available. Obviously, this does not mean the models built with 60 proteins are better than the RMSECV models built using the 85 proteins but it largely reflects the breadth of structure sampling in the test set. The $\alpha$-helix fraction is predicted at $\mathrm{t}_{15}$ with an error RMSEKS of $6.63 \%$ by PLS (Table 2) and RMSECV 5.68\% (Table 1) in cross-validation. Yet, the $\zeta^{\mathrm{KS}}$ and $\zeta^{\mathrm{CV}}$ scores are, respectively, 3.18 and 3.16 reflecting the fact that, even if RMSECV is higher than for the 25-protein set, the apparently better RMSE is due to a larger STDDEV ${ }^{\text {REFKS }}$ in the 


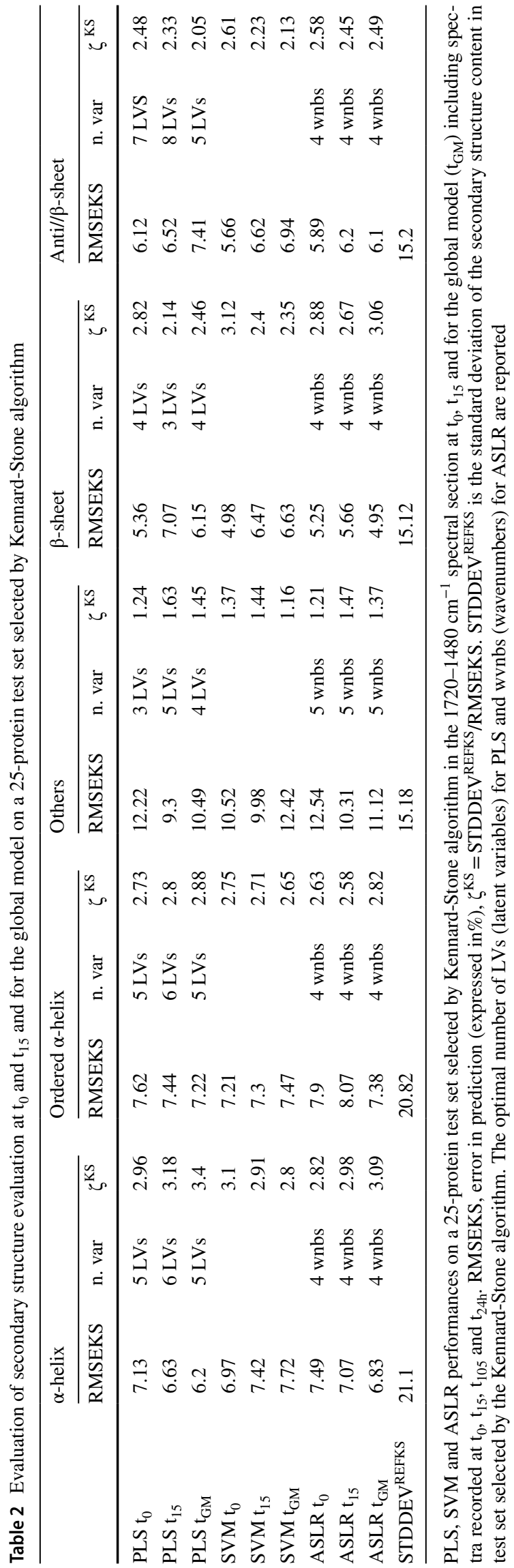

25 proteins selected by Kennard-Stone algorithm than in the full 85 protein set (21.1 and $17.9 \%$, respectively). However, it is important to note that the prediction remains good for a 25 -protein independent set. For $\beta$-sheets, the prediction is very good (RMSEKS around 5.0\%) at t0. The relatively poor prediction for the "Others" fraction (RMSEKS: 9.3\% in the best case) can be explained by the removal of the metallothionein from the calibration set (Table S1). Metallothionein is the sole intrinsically disordered protein in the 85 protein. This limitation is due to the fact that finding disordered proteins available with a high-resolution structure deposited in the PDB is indeed challenging. Because metallothionein is rather unique, to be correctly predicted, metallothionein must be part of the calibration set. In this case, the RMSEKS for "Others" will drops from 9.3 to $7.23 \%$ (not shown). The global overview presented in Tables 1 and 2 also indicates that the ordered helices are not better predicted than $\alpha$-helices (i.e. ordered and disordered helices taken together) at the opposite to previous observations reported in the literature (see "Introduction"). Similarly, the antiparallel $\beta$-sheet is not better predicted than the $\beta$-sheet (i.e. the antiparallel $\beta$-sheet and parallel $\beta$-sheet taken together).

The hydration level of the sample before deuteration starts could be a concern for protein structure stability and for FTIR spectra. Early works by Prestrelski et al. (Prestrelski et al. 1993; Carpenter et al. 1993) described that most proteins do not experience structural changes by lyophilization. It must be stressed that the samples used in this work are less desiccated than lyophilized samples. Protein films contain indeed a fair amount of water. It was determined by ${ }^{2} \mathrm{H}$ NMR combined with FTIR measurements that the lowest amount of water that can be reached upon exposing protein films to dry air was $0.13 \mathrm{~g}$ water per g protein (de Jongh et al. 1996). In uncontrolled conditions (open air), the amount of water was always above $0.25 \mathrm{~g}$ water per g protein. At that concentration, the water spectrum does not vary anymore with the water/protein ratio, the protein carboxylic and carbonyl sites are saturates (Careri et al. 1980) and enzyme activity can be measured for lysozyme (Careri et al. 1980). Poole and Finney (Poole and Finney 1984) reported the sequential hydration of lysozyme and $\alpha$-lactalbumin. For both proteins, most of the hydration effects occur below $0.13 \mathrm{~g}$ water per $\mathrm{g}$ protein. The rate of exchange was also found to reach a maximum above $0.15 \mathrm{~g}$ water per $\mathrm{g}$ protein (Schinkel et al. 1985). Altogether, these observations reported in the literature suggest that the effect of low hydration at the beginning of the experiments described here is negligible.

Hydrogen deuterium exchange (HDX) has long been used for protein structure and dynamics analysis by FTIR spectroscopy (Zhang et al. 1992; de-Jongh et al. 1995; de Jongh et al. 1997; Scheirlinckx et al. 2004), Raman (Hildebrandt et al. 1993), NMR (Wagner 1983; Zhang et al. 1995) and mass spectroscopy (Nabedryk-Viala et al. 1976; Engen 


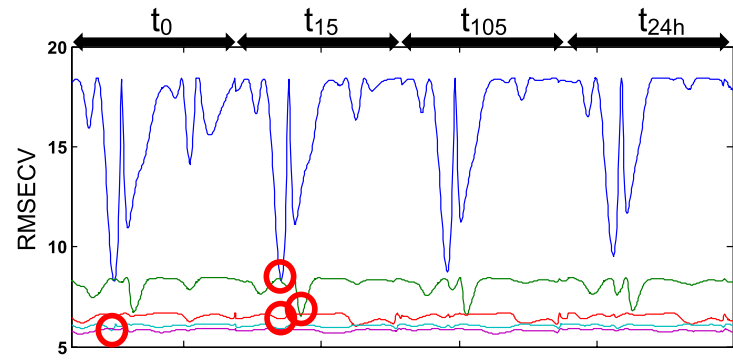

Wavenumbers, four $1720-1480 \mathrm{~cm}^{-1}$ sections

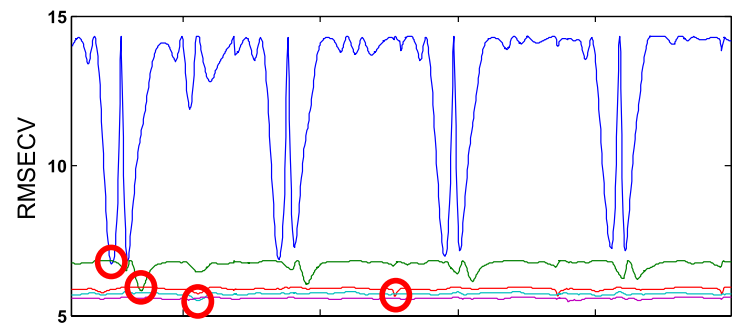

Wavenumbers, four $1720-1480 \mathrm{~cm}^{-1}$ sections

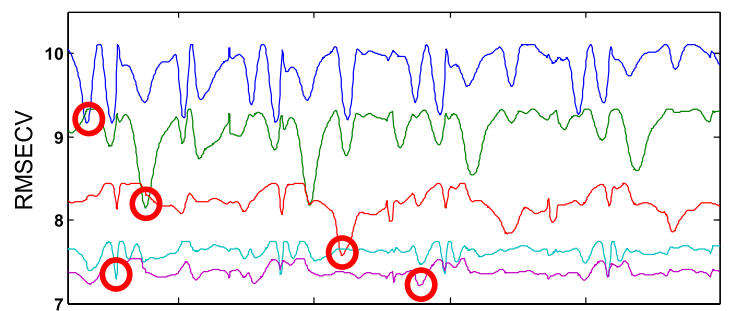

Wavenumbers, four $1720-1480 \mathrm{~cm}^{-1}$ sections
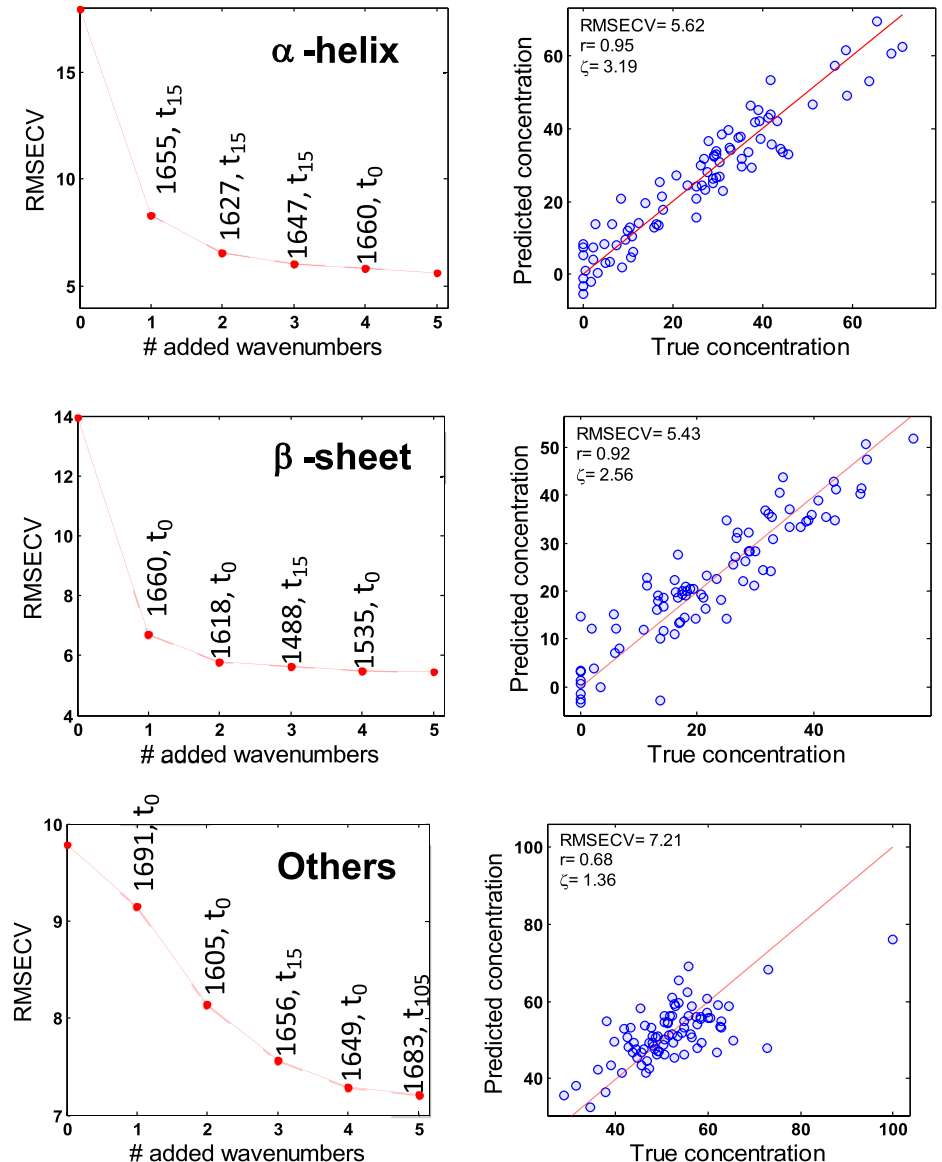

Fig. 6 Ascending stepwise linear regression. Top, $\alpha$-helix; middle, $\beta$-sheet; bottom, "Others". The left column presents the profile of the RMSECV (expressed in \% of the structure content) when a single wavenumber is used (blue line), when a second is added (green line), a third one (red line), a fourth one (cyan) and a fifth one (magenta). For each curve, the value of the minimum with the corresponding wavenumber is reported in the middle column. This wavenumber is added to the model and a new scan is started to identify the next best wavenumber that, when added to the previous ones, bring useful information for secondary structure prediction. The right column reports the predicted secondary structure content as a function of the actual content for each structure. The red diagonal line reflects a situation where prediction is perfect. All four deuteration time periods indicated on top of the left columns were used simultaneously. The best wavenumbers identified by a red circle are reported in the middle column.

Table 3 Wavenumbers selected by order of relevance for $\alpha$-helix, ordered $\alpha$-helix, $\beta$-sheet, antiparallel $\beta$-sheet and "Others" and their deuteration time. A colour code identifies each period: $\mathrm{t} 0$, green; $\mathrm{t} 15$, yellow and $\mathrm{t} 105$, red

\begin{tabular}{|cccccc|}
\hline & wvnb \#1 & wvnb \#2 & wvnb \#3 & wvnb \#4 & wvnb \#5 \\
$\alpha$-helix & 1655 & 1627 & 1647 & 1660 & \\
ordered $\alpha$-helix & 1657 & 1629 & 1496 & 1551 & \\
$\beta$-sheet & 1660 & 1618 & 1488 & 1535 & \\
anti// $\beta$-sheet & 1660 & 1620 & 1537 & 1491 & \\
"Others" & 1691 & 1605 & 1556 & 1649 & 1683 \\
\hline
\end{tabular}

Results were obtained for the entire concatenate spectra. Models obtained for each individual deuteration time are summarized in Table 1

and Smith 2000). Exchangeable hydrogens are distributed all along the main-chain and side chains of proteins. They participate to a dynamic process of exchange with hydrogen atoms of the solvent (Englander et al. 1996). They are also involved in hydrogens bonds that stabilize $\alpha$-helices and $\beta$-sheets. Solvent and protein protons exchange occurs naturally at variable exchange rates. The hydrogens of the peptide groups ( 1 hydrogen per amino acid except proline) exchange 

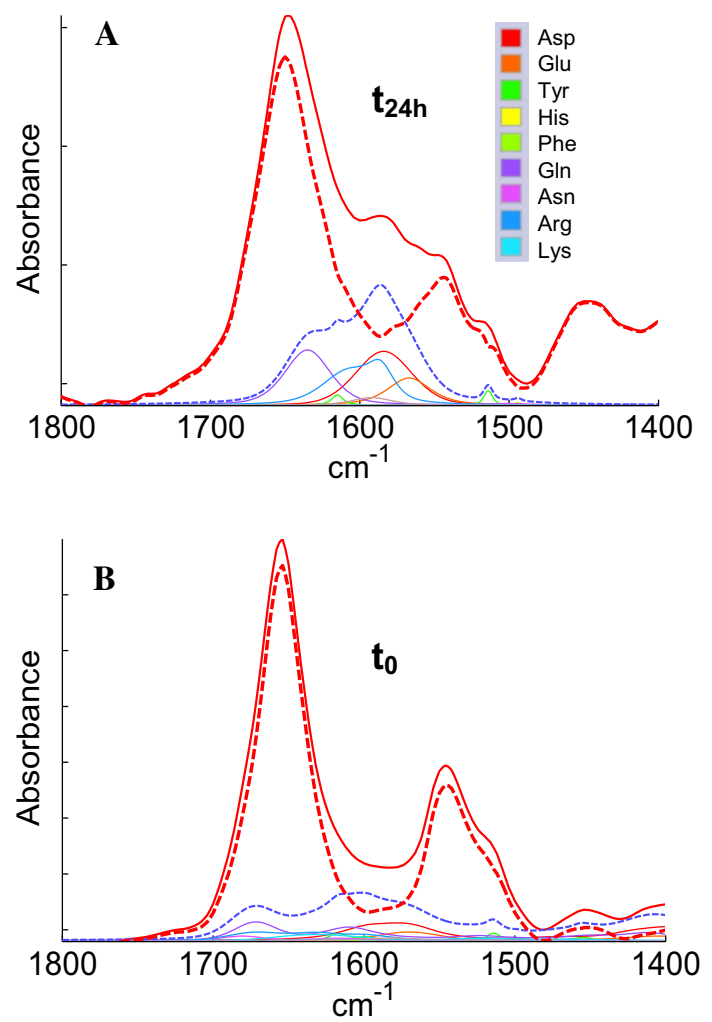

Fig. 7 Glucagon spectrum red plain line in the deuterated $\left(\mathrm{t}_{24 \mathrm{~h}}\right.$, panel A) and protonated $\left(\mathrm{t}_{0}\right.$, panel $\left.\mathrm{B}\right)$ forms. The contribution of the different side chains (see legend in panel A.) and their sum (blue dashed line) are presented in both cases. After subtraction of the side chain contributions, the corrected spectra appear as dashed red lines

at variable rates depending on their accessibility to solvent and involvement in H-bonds. They have therefore been used as sensors of the conformational state of the protein (Zhang et al. 1992, 1995; Goormaghtigh et al. 1994d, 2009; Englander et al. 1996; Raussens et al. 1996, 2004; Meskers et al. 1999; Scheirlinckx et al. 2004). In principle, hydrogens present in disordered structures are rapidly exchanged with deuterium when compared with protons involved in secondary structure stabilization or buried in hydrophobic clusters (Englander and Kallenbach 1983b; Englander et al. 1996; Skinner et al. 2012a; Englander and Mayne 2014). Yet, the static and dynamic determinants of the exchange remain unclear. Indeed, unexpected slow hydrogen exchange may be observed on the surface of proteins as well as fast exchange of buried hydrogen which may be related to mechanisms of transitional and localized unfolding (Englander and Kallenbach 1983b; Skinner et al. 2012b, a; Englander and Mayne 2014). The best performance obtained for $\alpha$-helix at the partial deuteration time period $t_{15}$ could be explained by the displacement towards lower wavenumbers (Fig. 2) of the protein fractions that exchange very quickly, likely composed of more accessible structures such as the unordered (random) fraction. As $\alpha$-helix and random absorbance bands overlap widely, their boundaries before deuteration are blurred and a separation induced by the partial H/D exchange leads to a better analysis of both the helices and "Others" contributions as observed in this paper. As these shifted contributions move towards lower wavenumbers, they overlap $\beta$-sheet contributions. This, with a further contribution of amino acid side chains, probably explains the observed degradation of $\beta$-sheet evaluation at $t_{15}$ with respect to $t_{0}$. It is also interesting to note that earlier determination of protein secondary structures from FTIR spectra were carried out on deuterated proteins (Byler and Susi 1986; Goormaghtigh et al. 1989, 1990), essentially to avoid the strong overlap between water $\mathrm{O}-\mathrm{H}$ bending and amide I (Pastrana-Rios 2001). The present work indicates that long deuteration time are not the best choice for secondary structure evaluation.

The present work confirms on a large set of proteins that neither are the ordered/disordered helices quantified better than the full $\alpha$-helix nor is the split of $\beta$-sheet into parallel and antiparallel adequate even though for some specific cases such as amyloid-forming proteins, it appears to be quite relevant (Cerf et al. 2009; Celej et al. 2012). In the present case, it is possible that the mix of sheets of various lengths and made out of various number of strands blurred the difference that is obvious in amyloid $\beta$ peptides.

Taken together, the results obtained in this work indicate that using deuteration do not bring a breakthrough in secondary structure prediction. There are several reasons why there is a limit to secondary structure prediction accuracy. The major one is related to the simplification of the secondary structure definition. The three classes, $\alpha$-helix, $\beta$-sheet and "Others" are far to form homogenous entities. While this is obvious for the "Others" that, by definition, groups a series of diverse structures described in the introduction, the $\alpha$-helix category for instance, also contains a wide variety of structural characteristics that yield different FTIR features (variation in band position and bandwidth). Some helices are long, other short, some are bended, some include kinks etc. All these structural characteristics affect the FTIR spectrum. There is therefore not one $\alpha$-helix spectrum but a wide variety of them centred on the "typical" $\alpha$-helix spectrum. The definition itself of the $\alpha$-helix structure relies on rather arbitrary cutoff for hydrogen bond energy or length/angle and backbone $\varphi / \psi$ angles. From a same high-resolution structure, we decided here to use DSSP designed by Kabsch and Sander (Kabsch and Sander 1983) but several other definitions have been proposed such as STRIDE (Frishman and Argos 1995), XTLSSTR (King and Johnson 1999), KAKSI (Martin et al. 2005), PALSSE (Majumdar et al. 2005) and STICK (Taylor 2001). These methods result, on the average, in $20 \%$ difference in the $\alpha$-helix content but the difference can be much larger for some proteins. In a previous work (De Meutter and Goormaghtigh 2020a), we showed that DSSP is 
one of the definitions that has the best match with the FTIR spectra. Yet, the different definitions highlight the difficulty to summarize the variations that exist in protein structure in a single category such as $\alpha$-helix. In addition to definition issues, the variance of a defined structure content may be insufficient to build a prediction model. For instance, the "Others" content in the present database has a mean value of $51.7 \%$ but a rather small standard deviation $(9.8 \%)$. Band overlap is another issue. The present work indicates that replacement of the amide proton by a deuteron is not sufficient to fully solve the problem. Another problem comes from side chain absorption in the amide I-amide II spectral region. This issue has been raised in this paper, e.g. in Fig. 7. The means to bring a perfect correction to side chain contributions are still lacking. Finally, the reference protein set used to calibrate the prediction is critical. The cSP92 protein set, with very well characterized protein sequence, purity and structure quality (De Meutter and Goormaghtigh 2020b) has been designed for this purpose. Yet, it must be emphasized that it contains only protein for which a high-resolution structure is available. The large class of intrinsically disordered proteins is an example of proteins for which it is difficult to obtain a high-resolution structure, as these proteins usually do not crystallize. There is therefore an obvious lack of representation of these proteins with respect to their expected natural abundance (Ward et al. 2004; Weathers et al. 2006). Finally, it must be noted that, in general, the high-resolution structures have been obtained on protein crystals where the protein structure may be slightly different from the conformation present in aqueous solution or in dry film. However, systematic comparison of X-ray and NMRderived structures indicate that both are very similar when the fluctuations inherent to NMR are taken into account, lending support to the validity of both methods to describe native in vivo structures (Faraggi et al. 2018). Regarding the comparison between FTIR data obtained for protein solution and "dry" film, it must be stressed that, as discussed above, the amount of water left in "dry" proteins is quite significant and the validity of "dry" film has been reviewed elsewhere (Goormaghtigh et al. 1999). FTIR spectra of proteins in the "dry" and solution state show definite differences but the quality of secondary structure prediction is identical, at least for the protein library tested (Goormaghtigh et al. 2009b). All together, the different limitations identified above suggest that we are reaching the limit of the accuracy of structure prediction from FTIR spectra of proteins.

Supplementary Information The online version contains supplementary material available at https://doi.org/10.1007/s00249-021-01502-y.

Author contributions The manuscript was written through contributions of all authors. All authors have given approval to the final version of the manuscript.
Funding This work was supported by the Fonds de la Recherche Scientifique-FNRS under Grant no. O001518F (EOS-convention \# 30467715). We thank the Walloon Region (SPW, DGO6, Belgium) for supporting the ROBOTEIN project within the frame of the EQUIP2013 program. E.G. is Research Director with the National Fund for Scientific Research (Belgium).

Data availability Materials will be available on request from the authors.

Code availability No software was written for this work.

\section{Compliance with ethical standards}

Conflict of interest No conflict of interest.

Open Access This article is licensed under a Creative Commons Attribution 4.0 International License, which permits use, sharing, adaptation, distribution and reproduction in any medium or format, as long as you give appropriate credit to the original author(s) and the source, provide a link to the Creative Commons licence, and indicate if changes were made. The images or other third party material in this article are included in the article's Creative Commons licence, unless indicated otherwise in a credit line to the material. If material is not included in the article's Creative Commons licence and your intended use is not permitted by statutory regulation or exceeds the permitted use, you will need to obtain permission directly from the copyright holder. To view a copy of this licence, visit http://creativecommons.org/licenses/by/4.0/.

\section{References}

Arrondo JL, Muga A, Castresana J, Goñi FM (1993) Quantitative studies of the structure of proteins in solution by Fourier-transform infrared spectroscopy. Prog Biophys Mol Biol 59:23-56. https://doi.org/10.1016/0079-6107(93)90006-6

Baello BI, Pancoska P, Keiderling TA (2000) Enhanced prediction accuracy of protein secondary structure using hydrogen exchange Fourier transform infrared spectroscopy. Anal Biochem 280:46-57. https://doi.org/10.1006/abio.2000.4483

Barth A (2000) The infrared absorption of amino acid side chains. Prog Biophys Mol Biol 74:141-173

Barth A (2007) Infrared spectroscopy of proteins. Biochim Biophys Acta 1767:1073-1101. https://doi.org/10.1016/j.bbabi o.2007.06.004

Byler DM, Susi H (1986) Examination of the secondary structure of proteins by deconvolved FTIR spectra. Biopolymers 25:469-487

Careri G, Gratton E, Yang PH, Rupley JA (1980) Correlation of IR spectroscopic, heat capacity, diamagnetic susceptibility and enzymatic measurements on lysozyme powder. Nature 284:572-573

Carpenter JF, Prestrelski SJ, Arakawa T (1993) Separation of freezing- and drying-induced denaturation of lyophilized proteins using stress-specific stabilization. I Enzyme activity and calorimetric studies. ArchBiochemBiophys 303:456-464

Celej MS, Sarroukh R, Goormaghtigh E et al (2012) Toxic prefibrillar $\alpha$-synuclein amyloid oligomers adopt a distinctive antiparallel $\beta$-sheet structure. Biochem J 443:719-726. https://doi. org/10.1042/BJ20111924 
Cerf E, Sarroukh R, Tamamizu-Kato S et al (2009) Antiparallel betasheet: a signature structure of the oligomeric amyloid betapeptide. Biochem J 421:415-423

Chirgadze YN, Fedorov OV, Trushina NP (1975) Estimation of amino acid residue side-chain absorption in the infrared spectra of protein solutions in heavy water. Biopolymers 14:679-694

de Jongh HH, Goormaghtigh E, Ruysschaertde-Jongh JMHH (1996) The different molar absorptivities of the secondary structure types in the amide I region: an attenuated total reflection infrared study on globular proteins. AnalBiochem 242:95-103

de Jongh HH, Goormaghtigh E, Ruysschaertde-Jongh JMHH (1997) Amide-proton exchange of water-soluble proteins of different structural classes studied at the submolecular level by infrared spectroscopy. Biochemistry 36:13603-13610

De Meutter J, Goormaghtigh E (2020a) Searching for a better match between protein secondary structure definitions and protein FTIR spectra. Anal Chem. https://doi.org/10.1021/ACS. ANALCHEM.0C03943

De Meutter J, Goormaghtigh E (2020b) A convenient protein library for spectroscopic calibrations. Comput Struct Biotechnol J 18:1864-1876. https://doi.org/10.1016/j.csbj.2020.07.001

De Meutter J, Goormaghtigh E (2021) FTIR imaging of protein microarrays for high throughput secondary structure determination. Anal Chem. https://doi.org/10.1021/acs.analchem.0c03677

De Meutter J, Derfoufi MK, Goormaghtigh E (2016) Analysis of protein microarrays by FTIR imaging. Biomed Spectrosc Imaging 5:145-154

De Meutter J, Vandenameele J, Matagne A, Goormaghtigh E (2017) Infrared imaging of high density protein arrays. Analyst 142:1371-1380. https://doi.org/10.1039/c6an02048h

de-Jongh HH, Goormaghtigh E, Ruysschaert JM, de Jongh HH (1995) Tertiary stability of native and methionine- 80 modified cytochrome $\mathrm{c}$ detected by proton-deuterium exchange using on-line Fourier transform infrared spectroscopy. Biochemistry $34: 172-179$

Derenne A, Claessens T, Conus C, Goormaghtigh E (2013) Infrared spectroscopy of membrane lipids. In: Encyclopedia of biophysics. Springer, Berlin, Heidelberg, pp 1074-1081

Derenne A, Derfoufi K-M, Cowper B et al (2020) FTIR spectroscopy as an analytical tool to compare glycosylation in therapeutic monoclonal antibodies. Anal Chim Acta 1112:62-71. https:// doi.org/10.1016/J.ACA.2020.03.038

Dimitrov DS (2012) Therapeutic proteins. Methods Mol Biol 899:1. https://doi.org/10.1007/978-1-61779-921-1_1

Downer NW, Bruchman TJ, Hazzard JH (1986) Infrared spectroscopic study of photoreceptor membrane and purple membrane. Protein secondary structure and hydrogen deuterium exchange. J BiolChem 261:3640-3647

Engen J, Smith D (2000) Investigating the higher order structure of proteins. Hydrogen exchange, proteolytic fragmentation, and mass spectrometry. Methods Mol Biol. https://doi. org/10.1385/1-59259-045-4:95

Englander SW, Kallenbach NR (1983a) Hydrogen exchange and structural dynamics of proteins and nucleic acids. Q Rev Biophys 16:521-655. https://doi.org/10.1017/S00335835000052 17

Englander SW, Kallenbach NR (1983b) Hydrogen exchange and structural dynamics of proteins and nucleic acids. Q Rev Biophys 16:521-655

Englander SW, Mayne L (2014) The nature of protein folding pathways. Proc Natl Acad Sci USA 111:15873-15880. https://doi. org/10.1073/pnas.1411798111

Englander S, Sosnick T, Englander J, Mayne L (1996) Mechanisms and uses of hydrogen exchange. Curr Opin Struct Biol. https:// doi.org/10.1016/S0959-440X(96)80090-X
Englander JJ, Del MC, Li W et al (2003) The structural distribution of cooperative interactions in proteins: analysis of the native state ensemble. PNAS 95:9903-9908. https://doi.org/10.1073/ pnas.95.17.9903

Faraggi E, Dunker A, Sussman J, Kloczkowski A (2018) Comparing NMR and X-ray protein structure: lindemann-like parameters and NMR disorder. J Biomol Struct Dyn. https://doi. org/10.1080/07391102.2017.1352539

Fearn T (2002) Assessing calibrations: SEP, RPD, RER and $R^{2}$. NIR News 13:12-13. https://doi.org/10.1255/nirn.689

Frishman D, Argos P (1995) Knowledge-based protein secondary structure assignment. Proteins 23:566-579. https://doi.org/10.1002/ prot.340230412

Geladi P, Kowalski BR (1986) Partial least-squares regression: a tutorial. Anal Chim Acta 185:1-17. https://doi.org/10.1016/00032670(86)80028-9

Ghorbani M, Zargar G, Jazayeri-Rad H (2016) Prediction of asphaltene precipitation using support vector regression tuned with genetic algorithms. Petroleum 2:301-306. https://doi. org/10.1016/j.petlm.2016.05.006

Goormaghtigh E (2009) FTIR Data Processing and Analysis Tools. In: Barth A, P.I.Haris (eds) Adv. Biomed. Spectrosc. (Biological and Biomedical Infrared Spectroscopy). IOS Press 104-128

Goormaghtigh E, De Meutter J, Vanloo B et al (1989) Evaluation of the secondary structure of apo B-100 in low-density lipoprotein (LDL) by infrared spectroscopy. Biochim Biophys Acta 1006:147-150. https://doi.org/10.1016/0005-2760(89)90338-x

Goormaghtigh E, Cabiaux V, Ruysschaert JM (1990) Secondary structure and dosage of soluble and membrane proteins by attenuated total reflection Fourier-transform infrared spectroscopy on hydrated films. Fed Eur Biochem Soc J 193:409-420

Goormaghtigh E, Cabiaux V, Ruysschaert JM (1994a) Determination of soluble and membrane protein structure by Fourier transform infrared spectroscopy. III. Secondary structures. Subcell Biochem 23:405-450

Goormaghtigh E, Cabiaux V, Ruysschaert JM (1994b) Determination of soluble and membrane protein structure by Fourier transform infrared spectroscopy. II. Experimental aspects, side chain structure, and H/D exchange. Subcell Biochem 23:363-403

Goormaghtigh E, Cabiaux V, Ruysschaert JM (1994c) Determination of soluble and membrane protein structure by Fourier transform infrared spectroscopy. I. Assignments and model compounds. Subcell Biochem 23:329-362

Goormaghtigh E, Vigneron L, Scarborough GA, Ruysschaert JM (1994d) Tertiary conformational changes of the Neurospora crassa plasma membrane $\mathrm{H}(+)$-ATPase monitored by hydrogen/deuterium exchange kinetics. A Fourier transformed infrared spectroscopy approach. J BiolChem 269:27409-27413

Goormaghtigh E, de-Jongh HH, Ruysschaert JM (1996) Relevance of protein thin films prepared for attenuated total reflection Fourier transform infrared spectroscopy: significance of the pH. Appl Spectrosc 50:1519-1527

Goormaghtigh E, Raussens V, Ruysschaert JM (1999) Attenuated total reflection infrared spectroscopy of proteins and lipids in biological membranes. Biochim Biophys Acta 1422:105-185

Goormaghtigh E, Ruysschaert JM, Raussens V (2006) Evaluation of the information content in infrared spectra for protein secondary structure determination. Biophys J 90:2946-2957

Goormaghtigh E, Gasper R, Benard A et al (2009) Protein secondary structure content in solution, films and tissues: redundancy and complementarity of the information content in circular dichroism, transmission and ATR FTIR spectra. Biochim BiophysActa-Proteins Proteomics 1794:1332-1343 
Hering JA, Innocent PR, Haris PI (2004) Towards developing a protein infrared spectra databank (PISD) for proteomics research. Proteomics 4:2310-2319

Hildebrandt P, Vanhecke F, Heibel G, Mauk A (1993) Structural changes in cytochrome c upon hydrogen-deuterium exchange. Biochemistry. https://doi.org/10.1021/BI00214A013

Hvidt A, Nielsen S (1966) Hydrogen exchange in proteins. Adv Protein Chem 21:287-386. https://doi.org/10.1016/S0065 -3233(08)60129-1

Iloro I, Narvaez D, Guillen N et al (2008) The kinetics of the hydrogen/deuterium exchange of epidermal growth factor receptor ligands. Biophys J 94:4041-4055

Kabsch W, Sander S (1983) Dictionary of protein secondary structure: pattern recognition of hydrogen-bonded and geometrical features. Biopolymers 22:2577-2637

Kalnin NN, Baikalov IA, Venyaminov SY (1990) Quantitative IR spectrophotometry of peptides compounds in water $(\mathrm{H} 2 \mathrm{O})$ solutions. III. Estimation of the protein secondary structure. Biopolymers 30:1273-1280

Kennard RW, Stone LA (1969) computer aided design of experiments. Technometrics 11:137-148. https://doi. org/10.1080/00401706.1969.10490666

King SM, Johnson WC (1999) Assigning secondary structure from protein coordinate data. Proteins Struct Funct Genet 35:313-320. https://doi.org/10.1002/(SICI)1097-0134(19990 515)35:3\%3c313::AID-PROT5\%3e3.0.CO;2-1

Leardi R, Nørgaard L (2005) Sequential application of backward interval partial least squares and genetic algorithms for the selection of relevant spectral regions. J Chemom 18:486-497

Lee DC, Haris PI, Chapman D, Mitchell RC (1990) Determination of protein secondary structure using factor analysis of infrared spectra. Biochemistry 29:9185-9193

Majumdar I, Krishna SS, Grishin NV (2005) PALSSE: a program to delineate linear secondary structural elements from protein structures. BMC Bioinformatics 6:202. https://doi. org/10.1186/1471-2105-6-202

Martin J, Letellier G, Marin A et al (2005) Protein secondary structure assignment revisited: a detailed analysis of different assignment methods. BMC Struct Biol 5:17. https://doi. org/10.1186/1472-6807-5-17

Meskers S, Ruysschaert JM, Goormaghtigh E (1999) Hydrogendeuterium exchange of streptavidin and its complex with biotin studied by 2D-attenuated total reflection fourier transform infrared spectroscopy. J Am Chem Soc 121:5115-5122

Nabedryk-Viala E, Thiéry C, Calvet P, Thiéry J (1976) Hydrogenisotope exchange of oxidized and reduced cytochrome c. A comparison of mass spectrometry and infrared methods. Eur J Biochem. https://doi.org/10.1111/J.1432-1033.1976.TB100 18.X

Navea S, Tauler R, de Juan A (2005) Application of the local regression method interval partial least-squares to the elucidation of protein secondary structure. Anal Biochem 336:231-242. https ://doi.org/10.1016/j.ab.2004.10.016

Navea S, Tauler R, Goormaghtigh E, de Juan A (2006) Chemometric tools for classification and elucidation of protein secondary structure from infrared and circular dichroism spectroscopic measurements. Proteins-Struct Funct Bioinforma 63:527-541

Nørgaard L, Saudland A, Wagner J et al (2000) Interval partial leastsquares regression ( $i$ PLS): a comparative chemometric study with an example from near-infrared spectroscopy. Appl Spectrosc 54:413-419. https://doi.org/10.1366/0003702001949500

Oberg KA, Ruysschaert JM, Goormaghtigh E (2003) Rationally selected basis proteins: a new approach to selecting proteins for spectroscopic secondary structure analysis. Prot Sci 12:2015-2031
Oberg KA, Ruysschaert JM, Goormaghtigh E (2004) The optimization of protein secondary structure determination with infrared and CD spectra. Eur J Biochem 271:2937-2948

Orengo CA, Michie AD, Jones S et al (1997) CATH: a hierarchic classification of protein domain structures. Structure 5:1093-1108

Pastrana-Rios B (2001) Mechanism of unfolding of a model helical peptide. Biochemistry 40:9074-9081. https://doi.org/10.1021/ bi0155145

Poole PL, Finney JL (1984) Sequential hydration of dry proteins: a direct difference IR investigation of sequence homologs lysozyme and alpha- lactalbumin. Biopolymers 23:1647-1666

Prestrelski SJ, Byler DM, Liebman MN (1992) Generation of a substructure library for the description and classification of protein secondary structure. II. Application to spectra-structure correlations in fourier transform infrared spectroscopy. Proteins Struct Funct Genet 14:440-450. https://doi.org/10.1002/prot.34014 0405

Prestrelski SJ, Tedeschi N, Arakawa T, Carpenter JF (1993) Dehydration-induced conformational transitions in proteins and their inhibition by stabilizers. Biophys J 65:661-671

Pribic R, van Stokkum IH, Chapman D et al (1993) Protein secondary structure from Fourier transform infrared and/or circular dichroism spectra. Anal Biochem 214:366-378

Rahmelow K, Hubner W, Ackermann T (1998) Infrared absorbances of protein side chains. Anal Biochem 257:1-11

Raussens V, Narayanaswami V, Goormaghtigh E et al (1996) Hydrogen/deuterium exchange kinetics of apolipophorin-III in lipidfree and phospholipid-bound states. An analysis by Fourier transform infrared spectroscopy. J Biol Chem 271:23089-23095

Raussens V, Ruysschaert JM, Goormaghtigh E (2004) Analysis of $\mathrm{H}-1 / \mathrm{H}-2$ exchange kinetics using model infrared spectra. Appl Spectrosc 58:68-82

Raynal B, Lenormand P, Baron B et al (2014) Quality assessment and optimization of purified protein samples: why and how? Microb Cell Fact 13:180. https://doi.org/10.1186/s12934-014-0180-6

Rogstad S, Yan H, Wang X et al (2019) Multi-attribute method for quality control of therapeutic proteins. Anal Chem. https://doi. org/10.1021/ACS.ANALCHEM.9B03808

Scheirlinckx F, Raussens V, Ruysschaert J-M, Goormaghtigh E (2004) Conformational changes in gastric $\mathrm{H}+/ \mathrm{K}+$-ATPase monitored by difference Fourier-transform infrared spectroscopy and hydrogen/deuterium exchange. Biochem J 382:121-129. https://doi. org/10.1042/BJ20040277

Schinkel J, Downer N, Rupley J (1985) Hydrogen exchange of lysozyme powders. Hydration dependence of internal motions. Biochemistry. https://doi.org/10.1021/BI00323A018

Sivakumar V, Wang R, Hastings G (2005) A1 reduction in intact cyanobacterial photosystem I particles studied by time-resolved stepscan Fourier transform infrared difference spectroscopy and isotope labeling. Biochemistry. https://doi.org/10.1021/BI0497493

Skinner JJ, Lim WK, Bédard S et al (2012a) Protein dynamics viewed by hydrogen exchange. Protein Sci 21:996-1005. https://doi. org/10.1002/pro.2081

Skinner JJ, Lim WK, Bédard S et al (2012b) Protein hydrogen exchange: testing current models. Protein Sci 21:987-995. https ://doi.org/10.1002/pro.2082

Surewicz W, Mantsch H (1988) New insight into protein secondary structure from resolution-enhanced infrared spectra. Biochim Biophys Acta. https://doi.org/10.1016/0167-4838(88)90107-0

Susi H (1972) Infrared spectroscopy-conformation. Methods Enzymol 26:455-472. https://doi.org/10.1016/S0076-6879(72)26024-4

Susi H, Byler DM (1986a) Resolution-enhanced Fourier transform infrared spectroscopy of enzymes. Methods Enzym 130:290-311

Susi H, Byler DM (1986b) Resolution-enhanced fourier transform infrared spectroscopy of enzymes. Methods Enzymol 130:290 311. https://doi.org/10.1016/0076-6879(86)30015-6 
Susi H, Byler DM (1987) Fourier transform infrared study of proteins with parallel beta- chains. Arch Biochem Biophys 258:465-469

Suykens JAK, Vandewalle J (1999) Least squares support vector machine classifiers. Neural Process Lett 9:293-300. https://doi. org/10.1023/A:1018628609742

Suykens JAK, De Brabanter J, Lukas L, Vandewalle J (2002) Weighted least squares support vector machines: robustness and sparse approximation. Neurocomputing 48:85-105. https://doi. org/10.1016/S0925-2312(01)00644-0

Tange R, Rasmussen MA, Taira E, Bro R (2015) Application of support vector regression for simultaneous modelling of near infrared spectra from multiple process steps. J Near Infrared Spectrosc 23:75-84. https://doi.org/10.1255/jnirs.1149

Taylor WR (2001) Defining linear segments in protein structure 1 1Edited by. J Thornton J Mol Biol 310:1135-1150. https://doi. org/10.1006/jmbi.2001.4817

Venyaminov SYY, Kalnin NN (1991) Quantitative IR spectrophotometry of peptides compounds in water $(\mathrm{H} 2 \mathrm{O})$ solutions. I. Spectral parameters of amino acid residue absorption band. Biopolymers 30:1243-1257

Vigano C, Smeyers M, Raussens V et al (2004) Hydrogen-deuterium exchange in membrane proteins monitored by IR spectroscopy: a new tool to resolve protein structure and dynamics. Biopolymers 74:19-26

Wagner G (1983) Characterization of the distribution of internal motions in the basic pancreatic trypsin inhibitor using a large number of internal NMR probes. Q Rev Biophys. https://doi. org/10.1017/S0033583500004911

Wang Y, Boysen RI, Wood BR et al (2008) Determination of the secondary structure of proteins in different environments by FTIRATR spectroscopy and PLS regression. Biopolymers 89:895905. https://doi.org/10.1002/bip.21022

Ward JJ, Sodhi JS, McGuffin LJ et al (2004) Prediction and functional analysis of native disorder in proteins from the three kingdoms of life. J Mol Biol 337:635-645. https://doi.org/10.1016/j. jmb.2004.02.002

Weathers EA, Paulaitis ME, Woolf TB, Hoh JH (2006) Insights into protein structure and function from disorder-complexity space. Proteins Struct Funct Bioinforma 66:16-28. https://doi. org/10.1002/prot.21055

Wilcox KE, Blanch EW, Doig AJ (2016) Determination of protein secondary structure from infrared spectra using partial least-squares regression. Biochemistry 55:3794-3802. https://doi.org/10.1021/ acs.biochem.6b00403

Wold S, Sjöström M, Eriksson L (2001) PLS-regression: a basic tool of chemometrics. Chemom Intell Lab 58:109-130. https://doi. org/10.1016/S0169-7439(01)00155-1

Wolpert M, Hellwig P (2006) Infrared spectra and molar absorption coefficients of the 20 alpha amino acids in aqueous solutions in the spectral range from 1800 to $500 \mathrm{~cm}(-1)$. Spectrochim Acta A Mol Biomol Spectrosc 64:987-1001. https://doi.org/10.1016/j. saa.2005.08.025

Zhang Z (2020) Complete extraction of protein dynamics information in hydrogen/deuterium exchange mass spectrometry data. Anal Chem 92:6486-6494. https://doi.org/10.1021/acs.analc hem.9b05724

Zhang Y, Lewis R, Hodges R, McElhaney RN (1992) FTIR spectroscopic studies of the conformation and amide hydrogen exchange of a peptide model of the hydrophobic transmembrane alpha-helices of membrane proteins. Biochemistry. https://doi. org/10.1021/BI00161A041

Zhang Y, Lewis RN, Henry GD et al (1995) Peptide models of helical hydrophobic transmembrane segments of membrane proteins. 1 . Studies of the conformation, intrabilayer orientation, and amide hydrogen exchangeability of Ac-K2-(LA)12-K2-amide. Biochemistry. https://doi.org/10.1021/BI00007A031

Zuber G, Prestrelski SJ, Benedek K (1992) Application of Fourier transform infrared spectroscopy to studies of aqueous protein solutions. Anal Biochem 207:150-156. https://doi. org/10.1016/0003-2697(92)90516-A

Publisher's Note Springer Nature remains neutral with regard to jurisdictional claims in published maps and institutional affiliations. 